\title{
Identification of SNPs in growth-related genes in Colombian creole cattle
}

\author{
R. Martinez ${ }^{1}$, J.F. Rocha ${ }^{2}$, D. Bejarano ${ }^{1}$, Y. Gomez ${ }^{1}$, Y. Abuabara ${ }^{3}$ and \\ J. Gallego 4 \\ ${ }^{1}$ Colombian Corporation of Agricultural Research, Tibaitata, Cundinamarca, \\ Colombia \\ ${ }^{2}$ Colombian Corporation of Agricultural Research, Obonuco, Nariño, Colombia \\ ${ }^{3}$ Colombian Corporation of Agricultural Research, Turipaná, Córdoba, Colombia \\ ${ }^{4}$ Colombian Corporation of Agricultural Research, El Nus, Antioquia, Colombia \\ Corresponding author: J.F. Rocha \\ E-mail: juanfelipemrocha@gmail.com / J.F.MartinezRocha@massey.ac.nz
}

Genet. Mol. Res. 15 (3): gmr.15038762

Received May 5, 2016

Accepted June 27, 2016

Published September 19, 2016

DOI http://dx.doi.org/10.4238/gmr.15038762

Copyright (C) 2016 The Authors. This is an open-access article distributed under the terms of the Creative Commons Attribution ShareAlike (CC BY-SA) 4.0 License.

\begin{abstract}
Colombian creole cattle have important adaptation traits related to heat tolerance and reproductive and productive efficiency. Romosinuano (ROMO) and Blanco Orejinegro (BON) are the most common breeds used by Colombian cattle breeders. Growth traits are of prime importance in these animals, which are mainly raised for beef production. Genes encoding growth hormone, growth hormone receptor, homeobox protein, insulin growth factor binding protein 3, leptin, and myostatin have been associated with physiological growth pathways in cattle and other species. We therefore aimed to identify single nucleotide polymorphisms (SNPs) within these genes in ROMO, $\mathrm{BON}$, and Zebu cattle. DNA regions of these genes were sequenced in 386 animals; 47 new SNPs were found, of which 14 were located in the exonic regions, thereby changing the protein sequence. An association
\end{abstract}


of SNPs with weaning weight (WW), daily weight gain at weaning (DWG), and weight at 16 months (W16M) traits was deduced. The genetic analysis revealed several SNPs related to these traits. The SNP GhRE06.2 had a significant association with WW and the SNP Lep03.4 was highly associated with DWG and W16M. Other polymorphisms were significantly associated with WW and DWG, although they did not surpass the Bonferroni significance threshold. The new mutations identified may indicate important points of genetic control in the DNA that could be responsible for changes in the expression of the analyzed traits. These SNPs might be used in future breeding programs to improve the productive performance of cattle in beef farms.

Key words: SNP; Growth traits; Blanco Orejinegro; Romosinuano; Creole cattle

\section{INTRODUCTION}

Growth traits in livestock animals are quantitative variables, often controlled by a large number of genes. Several studies have identified candidate genes associated with phenotypic variations in growth traits that might be responsible for the differences in productive performance observed among animals maintained under the same environmental conditions. Growth hormone (GH) and insulin-like growth factor-I (IGF-I) are molecules released from the pituitary and liver, respectively, which, along with their associated carrier proteins (IGF-binding proteins) and receptors, form the somatotropic (GH-IGF) axis that is thought to control growth and lactation (Pereira et al., 2005; Lucy, 2008).

High plasma GH levels have been detected in animals selected for increased growth rate. However, GH itself does not directly affect the growth rate. Instead, it interacts with a number of other hormones and growth factors, such as GH receptor (GHR) and insulin growth factor binding protein 3 (IGFBP-3), during various processes of synthesis, regulation, and molecule binding (Houba and te Pas, 2004). In cattle, different genes coding for proteins of the GH-IGF system have been implicated in physiological processes involved in energy homeostasis, growth regulation, and performance (Tuggle and Trenkle, 1996; Breier, 1999; Grochowska et al., 2001a; Biswas et al., 2003; Chagas et al., 2007; Velazquez et al., 2008; Arango et al., 2014). Interactions of the GH-IGF system with genes like HESX1 (homeobox protein) have been reported to be associated with GH deficiency or combined pituitary hormone deficiency (Takagi et al., 2016), as well as with cellular differentiation during the embryonic stage (Lai et al., 2009).

Other genes influencing the growth in animals have weaker interactions with the GH-IGF axis; however, they have been associated with important physiological functions and special muscle conditions. In bovine adipose tissue, growth hormone regulates the gene expression of leptin (Houseknecht et al., 2000), a hormone that functions as a lipostatic signal to regulate body weight $(\mathrm{BW})$, feed intake, expenditure energy, reproduction, and functions of the immune system (Houseknecht et al., 1998; Larsson et al., 1998; Lord et al., 1998; Woods et al., 1998; Cunningham et al., 1999; Delavaud et al., 2002; Garcia et al., 2002; Nkrumah et al., 2004). Genomic variations in leptin (LEPT) gene have been associated with growth traits in goats (Wang et al., 2015) and beef cattle (Tian et al., 2013). The phenomenon of

Genetics and Molecular Research 15 (3): gmr.15038762 
excessive muscle fiber formation in Belgian Blue and Piedmontese cattle, known as "doublemuscling," has been associated with myostatin (MSTN) gene (Rehfeldt et al., 2004). Several polymorphisms have been reported in the MSTN gene in Bos indicus cattle (Grisolia et al., 2009) and few single nucleotide polymorphism (SNPs) have been associated with growth traits in Marchigiana cattle (Sarti et al., 2014).

Blanco Orejinegro (BON) and Romosinuano (ROMO) are Colombian creole cattle breeds used in beef farms (Martínez, 1992, 1998). These animals have better fertility (Rocha et al., 2012) and productive performance than the overseas breeds, probably because of more than 500 years of adaptation to tropical conditions, leading to lower mortality rates, heat tolerance, and disease resistance (Vásquez et al., 2007; Martínez et al., 2009). Genome wide association studies have identified numerous SNPs associated with growth traits in these breeds (Martínez et al., 2014). However, the high genetic diversity reported in BON (Martínez et al., 2013) and ROMO (Bejarano et al., 2012) suggests the need for identification of new SNPs in candidate genes associated with growth traits for these creole breeds, which might not be present in the common set of SNPs covered by the existing genotyping arrays in cattle. The aim of this study was to identify SNPs in GH, GHR, HESX1, IGFBP-3, LEPT, and MSTN, evaluating their association with growth traits in Colombian Creole cattle breeds, BON and ROMO.

\section{MATERIAL AND METHODS}

\section{Population}

The study included $386 \mathrm{BON}$ and ROMO individuals, which were the descendants of 32 bulls, whose germplasm is kept in the germplasm bank of the Colombian Corporation for Agriculture Research, Mosquera, Colombia. All the steers were weaned at 8 months and fed on grass for up to 24 months. Subsequently, they were maintained under a strict, monthly controlled weighing program in the experimental units of Turipaná (Monteria, Cordoba), El Nus (San Roque, Antioquia), and Aguazul (Casanare). These animals were selected from a population of 950 candidates using breeding values for weaning weight (WW) and weight at 16 months (W16M). Mineral salt, fresh roughage, and water were offered ad libitum to the animals. Live weights were determined before slaughtering the animals. The genotyping only included animals with the highest and lowest breeding values, equally distributed among the groups within the breeds.

The present study did not require ethical clearance from the Animal Care and Use Committee because the data were extracted from existing herd books and the biological samples and genetic materials had been obtained for previous studies and were stored in germplasm banks.

\section{DNA extraction and polymerase chain reaction}

Blood samples were obtained from 386 animals (186 ROMO, 171 BON and 29 Zebu). DNA was extracted following a standard commercial protocol (MoBio Laboratories, Inc., Carlsbad, CA, USA) whereas a phenol-chloroform protocol (Sambrook and Russell, 2001) was used for extraction from thawed straws. After extraction, the quality and quantity of DNA samples were estimated by a spectrophotometer (Nanodrop $2000^{\circledR}$, Thermo Scientific, USA) and each sample was diluted to $50 \mathrm{ng} / \mu \mathrm{L}$ and stored at $-70^{\circ} \mathrm{C}$, until further use in polymerase chain reaction (PCR).

Genetics and Molecular Research 15 (3): gmr.15038762 
For amplification and sequence analysis, sixty sets of primers were designed, based on GenBank sequences, using the ENSEMBL database1 and the Btau_4.0 (October 2007) assembly (GenBank accession No. ENSBTAG00000011082). Bovine specific PCR primers were designed using Primer3 program (Rozen and Skaletsky, 2000). The NCBI primer BLAST tool2 was used to amplify approximately 1000-bp fragments of the gene flanking the SNPs identified in ENSEMBL.

\section{Sequencing analysis}

The genotyping reaction was based on a multiplex PCR followed by a templatedirected single-base extension using a probe. The products were separated and detected by mass spectrometry (MALDI-TOF MS) (Ehrich et al., 2005). The genotyping analysis was carried out by Sequenom ${ }^{\circledR}$ iPLEX $^{\circledR}$ Gold Technology at the Genome Quebec Innovation Center, Canada. The call rate was close to $92 \%$ and the error rate was less than $0.1 \%$.

The edited sequences were analyzed using the BLAST tool from NCBI to confirm their position on corresponding bovine chromosome. The sequences of six genes were deposited in the GenBank database and included in the Sequin software. The sequences were submitted and released on December 2012. The SNP positions were based on the sequences with GenBank accession No. JQ711177 for GHR, JQ711178 for HESX1, JQ711179 for LEPT, JQ711180 for MSTN, and JQ711181 for IGFBP-3.

Several SNPs from sequences of the six genes were studied using the Phred/Phrap/ Polyphred/Consed pipeline (Nickerson et al., 1997; Ewing et al., 1998; Ewing and Green 1998; Gordon et al., 1998). In total, 965 contigs were obtained after assembling with the Phred and Phrap programs (Ewing et al., 1998; Ewing and Green 1998) from the Genome Sciences Department of Washington University and the Howard Hughes Medical Institute (http://www.phrap.org). Contigs containing two or more sequence reads were selected for analysis with Polyphred, obtaining 47 high-quality candidate cSNPs from a total of 129 contigs. All the SNPs were confirmed visually. Finally, multiple alignment was done to compare the obtained sequences with those in the public database for all the six genes for Bos taurus and B. indicus, using BLASTn (NCBI). The SNPs and insertions or deletions were identified using the software PolyPhred 6.18 and PolyScan. The polymorphisms identified were compared among the breeds and among the groups within the same breed. The sequence information was used to define the coding and non-coding regions and to establish the number of SNP variants on each gene.

\section{Genotype analysis and genomic association}

The chi-square tests were used to determine whether an individual variant was in equilibrium at each locus in the population (Hardy-Weinberg equilibrium). The linkage disequilibrium (LD) was measured between all the pairs of bi-allelic loci, D' [the correlation coefficient (Delta, |D'|)], LOD (logarithm of odds), and $\mathrm{r}^{2}$. The strength of LD between pairs of SNPs was measured as D' using Haploview.

The phenotypic information was adjusted by age at each weight, from birth up to 16 months. The breed, group (high vs low breeding values), and sex were used as the fixed effects. Fifty-six significant SNPs were analyzed, all located on coding regions of the six genes, GH, GHR, HESX1, IGFBP-3, LEPT, and MSTN.

Genetics and Molecular Research 15 (3): gmr.15038762 
The association analysis was performed using a regression approach implemented in the SNPassoc package (González et al., 2007) of the statistical software R (CRAN, ver. 2.10.0, 2011). Five genetic inheritance models were tested. Each SNP was considered a categorical variable with one level for each possible genotype (co-dominant model), one level for the dominant genotype, and other level for the heterozygote and homozygote genotypes (dominant or recessive model) and one level for each additional copy of allele (additive model). To estimate the association between phenotype Y [BW, daily weight gain (DWG), and W16M] and one SNP, a lineal general model was used:

$$
Y i=\alpha+\beta X i+e i ; \quad L R T=2\left(\log L i k_{\text {null }}-\log L i k_{\text {other }}\right) \quad \text { (Equation 1) }
$$

where, $\alpha$ is the intercept, $X i$ is the $\mathrm{i}^{\text {th }}$ subject's genotype score for a given marker, and $e i$ is the error that has a normal distribution with expectation 0 and variance $d^{2}$. Under an additive model, $X i$ indicates $i^{\text {th }}$ subject's number of minor alleles. Under the dominant model, $X i$ denotes, with coded values 1 and 0 , whether the $i^{\text {th }}$ subject has at least one minor allele. Likewise, under the recessive (or over-dominant) model, $X i$ is codified as either 1 or 0 depending on whether the $\mathrm{i}^{\text {th }}$ subject has two minor alleles (or, in the over-dominant model, two minor or two major alleles).

Proportions of probability, differences, and confidence intervals were estimated for each genetic model using the variance values for every single parameter. The statistical significance of each SNP was assessed by comparing the polymorphism effect with one null model (which only included the intercept) through the likelihood ratio test

$$
L R T=2\left(\log L i k_{\text {null }}-\log L i k_{\text {other }}\right)
$$

where "other" refers to the genetic model. When this test was not sensitive enough to discriminate between the models, the Akaike information criterion (AIC) was useful in choosing the right inheritance model and the optimal model was attributed to that with the least AIC. AIC $=-2 \log$ Lik $+2 q$, where q denotes the number of parameters for the fitted model.

The evaluation of the interaction among SNPs implies the study of more than one SNP simultaneously, which can be estimated with the interaction Pval function. For each pair of SNPs $(i, j)$ this function calculates: Lik ${ }_{n u l}$, the likelihood underlying the null model, $\mathrm{Lik}_{i}$ and $\mathrm{Lik}_{j}$, the likelihood under each of the single-SNPs, Lik ${ }_{a d(i ; j)}$, the likelihood under an additive SNP model, and $\mathrm{Lik}_{\text {full }(i, j)}$, the likelihood under a full SNP model (including the SNP-SNP interaction). Here, SNPassoc uses the object-oriented features of R (classes and methods) to plot interaction analysis. The upper triangle in the matrix contains the P-values for the epistasis log-LRT.

$$
L R T_{i j}=-2\left(\log L i k_{f u l l(i ; j)}-\log \operatorname{Li} k_{a d(i ; j)}\right)
$$

(Equation 3)

The diagonal has the LRT P-values for the raw effect of each SNP

$$
L R T_{i i}=-2\left(\log L i k_{i}-\log L i k_{\text {null }}\right)
$$

Genetics and Molecular Research 15 (3): gmr.15038762 
The lower triangle comprises the LRT P values, comparing the two-SNP additive likelihood to the best of the single-SNP models.

$$
L R T_{j i}=-2\left(\log \operatorname{Lik}_{a d(; j)}-\log \max \left(\operatorname{Lik}_{i} ; \operatorname{Lik}_{j}\right)\right) \quad \text { (Equation 5) }
$$

\section{RESULTS}

Forty-seven new polymorphisms were identified within the exons, 14 of which produced changes in the protein sequence they encoded, and 24 SNPs were found in the non-coding regions. Ten polymorphisms (not previously reported in cattle) were found in the coding regions of the GH gene, with three of them generating changes in the protein sequence, as shown in Table 1. Three polymorphisms located between 2047 to $2246 \mathrm{bp}$ on exon V, caused changes in the protein sequence. The first SNP at $2050 \mathrm{bp}(\mathrm{C}>\mathrm{G})$ produced the amino acid change (Ala $>$ Gly), the second SNP $(2167 \mathrm{C}>\mathrm{T})$ caused the change (Pro $>\mathrm{Leu})$, and the last one $(2200 \mathrm{~A}>\mathrm{C})$ produced a change (Glu $>$ Ala). The SNP 2192C $>$ T represented a synonymous mutation (Table 2).

Table 1. Amino acid changes and allele frequencies caused by SNP polymorphisms in the GH, LEP, MSTN, GHR, HESX1, and IGFBP-3 genes of BON and ROMO cattle.

\begin{tabular}{|c|c|c|c|c|c|}
\hline Gene-SNP name & Change & Position & Amino acid change & \multicolumn{2}{|c|}{ Allele Frequency } \\
\hline Gh-SNP 1 & $\mathrm{C}>\mathrm{G}$ & Exon $\mathrm{V}$ & Ala $(\mathrm{GCT})>$ Gly $(\mathrm{GCT})$ & $\mathrm{C}(67.9 \%)$ & $\mathrm{G}(32.1 \%)$ \\
\hline Gh-SNP 2 & $\mathrm{C}>\mathrm{T}$ & Exon $\mathrm{V}$ & Pro $(\mathrm{CCG})>$ Leu $(\mathrm{CTG})$ & $\mathrm{C}(91.0 \%)$ & $\mathrm{T}(9.0 \%)$ \\
\hline Gh-SNP 3 & $\mathrm{C}>\mathrm{T}$ & Exon V & Synonymous substitution & $\mathrm{C}(98.7 \%)$ & $\mathrm{T}(1.3 \%)$ \\
\hline Gh-SNP 4 & $\mathrm{~A}>\mathrm{C}$ & Exon V & Glu (GAG)> Ala (GCG) & $\mathrm{A}(76.9 \%)$ & $\mathrm{C}(23.1 \%)$ \\
\hline Lep-SNP 1 & $\mathrm{~A}>\mathrm{T}$ & Exon I & Tyr $($ TAT) $>$ Phe (TTT) & $\mathrm{A}(87.5 \%)$ & $\mathrm{T}(12.5 \%)$ \\
\hline Lep-SNP 2 & $\mathrm{~T}>\mathrm{C}$ & Exon II & Cys $(\mathrm{TGC})>(\operatorname{Arg}(\mathrm{CGC})$ & $\mathrm{T}(91.4 \%)$ & $\mathrm{C}(8.6 \%)$ \\
\hline Lep-SNP 3 & $\mathrm{C}>\mathrm{T}$ & Intron & N/A & $\mathrm{C}(90.3 \%)$ & $\mathrm{T}(9.7 \%)$ \\
\hline Lep-SNP 4 & $\mathrm{C}>\mathrm{T}$ & Exon II & Ala $(\mathrm{GCG})>\operatorname{Val}(\mathrm{GTC})$ & $\mathrm{C}(76.3 \%)$ & $\mathrm{T}(23.7 \%)$ \\
\hline Lep-SNP 5 & $\mathrm{C}>\mathrm{T}$ & ExonII & (Gly) synonymous & $\mathrm{C}(72.4 \%)$ & $\mathrm{T}(27.6 \%)$ \\
\hline Lep-SNP 6 & $\mathrm{~T}>\mathrm{C}$ & ExonII & (Val) synonymous & $\mathrm{T}(71.1 \%)$ & $\mathrm{C}(28.9 \%)$ \\
\hline Lep-SNP 7 & $\mathrm{~T}>\mathrm{C}$ & ExonII & (Ala) synonymous & $\mathrm{T}(61.8 \%)$ & $\mathrm{C}(38.2 \%)$ \\
\hline Lep-SNP 8 & $\mathrm{C}>\mathrm{T}$ & ExonII & (Pro) synonymous & $\mathrm{C}(69.7 \%)$ & $\mathrm{T}(30.3 \%)$ \\
\hline Mstn-SNP 1 & $\mathrm{G}>\mathrm{C}$ & Exon & (Gly) synonymous & $\mathrm{G}(94.9 \%)$ & $\mathrm{C}(5.1 \%)$ \\
\hline Mstn-SNP 2 & $\mathrm{~A}>\mathrm{G}$ & Exon & Glu (GAA) >Asp (GAC) & $\mathrm{A}(87.2 \%)$ & $\mathrm{G}(12.8 \%)$ \\
\hline Mstn-SNP 3 & $\mathrm{~A}>\mathrm{G}$ & Intron & N/A & $\mathrm{A}(70.8 \%)$ & $\mathrm{G}(29.2 \%)$ \\
\hline Mstn-SNP 5 & $\mathrm{~T}>\mathrm{C}$ & Exon & (Cys) synonymous & $\mathrm{C}(59.5 \%)$ & $\mathrm{T}(40.5 \%)$ \\
\hline Mstn-SNP 6 & Insertion $\mathrm{T}$ & Intron & N/A & Normal (55.1\%) & Insertion $(44.9 \%)$ \\
\hline Mstn-SNP 7 & $\mathrm{~A}>\mathrm{C}$ & Exon & (Ile) synonymous & A $(78.6 \%)$ & $\mathrm{C}(21.4 \%)$ \\
\hline Mstn-SNP 8 & $\mathrm{C}>\mathrm{T}$ & Exon & (Tyr) synonymous & $\mathrm{C}(73.1 \%)$ & $\mathrm{T}(26.9 \%)$ \\
\hline Mstn-SNP 9 & $\mathrm{G}>\mathrm{A}$ & Exon & (Lys) synonymous & $\mathrm{G}(89.3 \%)$ & $\mathrm{A}(10.7 \%)$ \\
\hline Mstn-SNP 10 & $\mathrm{~T}>\mathrm{G}$ & UTR & $\mathrm{N} / \mathrm{A}$ & $\mathrm{T}(92.9 \%)$ & $\mathrm{G}(7.1 \%)$ \\
\hline rGH-SNP 1 & $\mathrm{C}>\mathrm{T}$ & ExonV & (Tyr) synonymous & $\mathrm{C}(97.2 \%)$ & $\mathrm{T}(2.8 \%)$ \\
\hline rGH-SNP 1 & $\mathrm{~T}>\mathrm{C}$ & ExonV & (Ser) synonymous & $\mathrm{T}(86.1 \%)$ & $\mathrm{C}(13.9 \%)$ \\
\hline rGH-SNP 1 & $\mathrm{~A}>\mathrm{G}$ & ExonV & (Thr) synonymous & $\mathrm{A}(94.4 \%)$ & $\mathrm{G}(5.6 \%)$ \\
\hline rGH-SNP 1 & $\mathrm{G}>\mathrm{A}$ & Exon $\mathrm{X}$ & Ser $(A G C)>A s n(A A C)$ & $\mathrm{G}(97.4 \%)$ & $\mathrm{A}(2.6 \%)$ \\
\hline rGH-SNP 2 & $\mathrm{C}>\mathrm{T}$ & Exon $\mathrm{X}$ & Pro $(\mathrm{CCC})>\operatorname{Ser}(\mathrm{TCC})$ & $\mathrm{C}(97.4 \%)$ & $\mathrm{T}(2.6 \%)$ \\
\hline rGH-SNP 3 & $\mathrm{~A}>\mathrm{G}$ & Exon $\mathrm{X}$ & Asn $(\mathrm{AAC})>\operatorname{Asp}(\mathrm{GAC})$ & A $(92.3 \%)$ & $\mathrm{G}(7.7 \%)$ \\
\hline rGH-SNP 4 & $\mathrm{~A}>\mathrm{C}$ & Exon $\mathrm{X}$ & Asn $(\mathrm{AAC})>\operatorname{Thr}(\mathrm{ACC})$ & $\mathrm{C}(52.6 \%)$ & $\mathrm{A}(47.4 \%)$ \\
\hline rGH-SNP 5 & $\mathrm{G}>\mathrm{A}$ & Exon $\mathrm{X}$ & Ala $(\mathrm{GCC})>\operatorname{Thr}(\mathrm{ACC})$ & $\mathrm{G}(98.7 \%)$ & $\mathrm{A}(1.3 \%)$ \\
\hline rGH-SNP 6 & $\mathrm{~A}>\mathrm{G}$ & Exon $\mathrm{X}$ & Ser $(\mathrm{AGC})>$ Gly $(\mathrm{GGC})$ & $\mathrm{A}(56.4 \%)$ & $\mathrm{G}(43.6 \%)$ \\
\hline Hesx-SNP1 & $\mathrm{C}>\mathrm{T}$ & Exon II & Pro $(\mathrm{CCT})>$ Leu $(\mathrm{CTT})$ & $\mathrm{C}(89.7 \%)$ & $\mathrm{T}(10.3 \%)$ \\
\hline Hesx-SNP2 & $\mathrm{G}>\mathrm{A}$ & Exon & (Pro) synonymous & $\mathrm{G}(89.7 \%)$ & $\mathrm{A}(10.3 \%)$ \\
\hline IgfBP-3-SNP1 & $\mathrm{C}>\mathrm{G}$ & Intron & N/A & $\mathrm{C}(89.2 \%)$ & $\mathrm{G}(10.8 \%)$ \\
\hline IgfBP-3-SNP2 & $\mathrm{C}>\mathrm{A}$ & Intron & N/A & $\mathrm{C}(64.9 \%)$ & $\mathrm{A}(35.1 \%)$ \\
\hline IgfBP-3-SNP3 & $\mathrm{C}>\mathrm{T}$ & UTR & N/A & $\mathrm{C}(63.9 \%)$ & $\mathrm{T}(36.1 \%)$ \\
\hline IgfBP-3-SNP4 & $\mathrm{T}>\mathrm{C}$ & Intron & N/A & $\mathrm{T}(60.3 \%)$ & $\mathrm{C}(39.7 \%)$ \\
\hline IgfBP-3-SNP5 & Deletion G & Intron & N/A & Normal $(89.7 \%)$ & Deletion $(10.3 \%)$ \\
\hline
\end{tabular}

Genetics and Molecular Research 15 (3): gmr.15038762 
Table 2. SNPs located within GH gene in ROMO and BON cattle breeds.

\begin{tabular}{l|c|c|c|c}
\hline & SNP1 & SNP2 & SNP3 & SNP4 \\
\hline Genotype & $\mathrm{C}>\mathrm{G}$ & $\mathrm{C}>\mathrm{T}$ & $\mathrm{C}>\mathrm{T}$ & $\mathrm{A}>\mathrm{C}$ \\
\hline Position & $\mathrm{Exon}$ & Exon & Exon & Exon \\
\hline \multirow{2}{*}{ AA Change } & Ala (GCT) & Pro (CCG) & No change & Glu (GAG) \\
\cline { 2 - 5 } & $\mathrm{Gly}(\mathrm{GCT})$ & Leu (CTG) & $\mathrm{C}(98.7 \%)$ & Ala (GCG) \\
\cline { 2 - 5 } & $\mathrm{C}(67.9 \%)$ & $\mathrm{C}(91.0 \%)$ & $\mathrm{T}(1.3 \%)$ & $\mathrm{A}(76.9 \%)$ \\
\cline { 2 - 5 } & $\mathrm{G}(32.1 \%)$ & $\mathrm{T}(9.0 \%)$ & $38(97.4 \%)$ & $\mathrm{C}(23.1 \%)$ \\
\cline { 2 - 5 } & $14(35.9 \%)$ & $32(82.1 \%)$ & $0(0.0 \%)$ & $3(7.7 \%)$ \\
\cline { 2 - 5 } & $0(0.0 \%)$ & $0(0.0 \%)$ & $1(2.6 \%)$ & $12(30.8 \%)$ \\
\hline
\end{tabular}

Three exons encoding the LEPT gene were sequenced and eight variants were identified (Table 3). There was a high frequency for the polymorphisms SNP5, SNP6, SNP7, and SNP8, located on the exon II ( $>0.27)$. Among these, only three showed amino acid changes in the protein sequence: the SNP $12730 \mathrm{bpA}>\mathrm{T}$ in exon I produced an amino acid change (Tyr $>$ Phe), whereas the SNPs 14706bpA $>$ T and $14863 \mathrm{bpC}>\mathrm{T}$ in exon II produced the amino acid changes (Cys $>$ Arg) and (Ala $>$ Val), respectively.

Table 3. SNPs located within the LEPT gene in ROMO and BON cattle breeds.

\begin{tabular}{|c|c|c|c|c|c|c|c|c|}
\hline & SNP1 & SNP2 & SNP3 & SNP4 & SNP5 & SNP6 & SNP7 & SNP8 \\
\hline Genotype & $\mathrm{A}>\mathrm{T}$ & $\mathrm{T}>\mathrm{C}$ & $\mathrm{C}>\mathrm{T}$ & $\mathrm{C}>\mathrm{T}$ & $\mathrm{C}>\mathrm{T}$ & $\mathrm{T}>\mathrm{C}$ & $\mathrm{T}>\mathrm{C}$ & $\mathrm{C}>\mathrm{T}$ \\
\hline Position & Exon I & Exon II & Intron & Exon II & Exon II & Exon II & Exon II & Exon II \\
\hline AA change & $\begin{array}{l}\text { Tyr (TAT) } v s \\
\text { Phe (TTT) }\end{array}$ & $\begin{array}{l}\text { Cys (TGC) vs } \\
\text { (Arg (CGC) }\end{array}$ & N/A & $\begin{array}{l}\text { Ala (GCG) } v s \text { Val } \\
\text { (GTC) }\end{array}$ & $\begin{array}{l}\text { No change } \\
\text { (Gly) }\end{array}$ & $\begin{array}{c}\text { No change } \\
\text { (Val) }\end{array}$ & $\begin{array}{c}\text { No change } \\
\text { (Ala) }\end{array}$ & $\begin{array}{c}\text { No change } \\
\text { (Pro) }\end{array}$ \\
\hline \multirow[t]{2}{*}{ Allele frequency } & $\mathrm{A}(87.5 \%)$ & $\mathrm{T}(91.4 \%)$ & C (90.3\%) & C (76.3\%) & C (72.4\%) & $\mathrm{T}(71.1 \%)$ & $\mathrm{T}(61.8 \%)$ & $\mathrm{C}(69.7 \%)$ \\
\hline & $\mathrm{T}(12.5 \%)$ & $\mathrm{C}(8.6 \%)$ & $\mathrm{T}(9.7 \%)$ & $\mathrm{T}(23.7 \%)$ & $\mathrm{T}(27.6 \%)$ & C (28.9\%) & C (38.2\%) & $\mathrm{T}(30.3 \%)$ \\
\hline
\end{tabular}

Nine variants were found in the MSTN gene (Table 4), of which six were identified in the coding regions, two in the non-coding regions, and one in an untranslated region. However, only the SNP2 1000bpA $>$ G in exon I caused an effective amino acid change (Glu $>$ Asp). Other variants were synonymous substitutions, with no effect on the protein sequence. Likewise, a thymine insertion was identified at $5263 \mathrm{bp}$ of an intronic region of MSTN.

Table 4. SNPs located within the MSTN gene in ROMO and BON cattle breeds respectively.

\begin{tabular}{|c|c|c|c|c|c|c|c|c|c|}
\hline & SNP1 & SNP2 & SNP3 & SNP5 & SNP6 & SNP7 & SNP8 & SNP9 & SNP10 \\
\hline Genotype & $\mathrm{G}>\mathrm{C}$ & $\mathrm{A}>\mathrm{G}$ & $\mathrm{A}>\mathrm{G}$ & $\mathrm{T}>\mathrm{C}$ & Insertion T & $\mathrm{A}>\mathrm{C}$ & $\mathrm{C}>\mathrm{T}$ & $\mathrm{G}>\mathrm{A}$ & $\mathrm{T}>\mathrm{G}$ \\
\hline Position & Exon & Exon & Intron & Exon & Intron & Exon & Exon & Exon & UTR \\
\hline AA change & $\begin{array}{l}\text { No change } \\
\text { (Gly) }\end{array}$ & $\begin{array}{c}\text { Glu (GAA) vs } \\
\text { Asp (GAC) }\end{array}$ & N/A & $\begin{array}{c}\text { No change } \\
\text { (Cys) }\end{array}$ & $\mathrm{N} / \mathrm{A}$ & $\begin{array}{c}\text { No change } \\
\text { (Ile) }\end{array}$ & $\begin{array}{l}\text { No change } \\
\text { (Tyr) }\end{array}$ & $\begin{array}{l}\text { No change } \\
\text { (Lys) }\end{array}$ & N/A \\
\hline \multirow[t]{2}{*}{ Allele frequency } & G (94.9\%) & $\mathrm{A}(87.2 \%)$ & $\mathrm{A}(70.8 \%)$ & C (59.5\%) & Normal (55.1\%) & $\mathrm{A}(78.6 \%)$ & $\mathrm{C}(73.1 \%)$ & $\mathrm{G}(89.3 \%)$ & T (92.9\%) \\
\hline & C (5.1\%) & $\mathrm{G}(12.8 \%)$ & G (29.2\%) & $\mathrm{T}(40.5 \%)$ & Insertion $(44.9 \%)$ & $\mathrm{C}(21.4 \%)$ & $\mathrm{T}(26.9 \%)$ & $\mathrm{A}(10.7 \%)$ & $\mathrm{G}(7.1 \%)$ \\
\hline
\end{tabular}

Thirty-seven SNPs were found in the GHR gene, of which 22 were located within the intronic regions, 2 in the 3 '-UTR region, and 13 in the coding regions. Only six variations were non synonymous and produced an amino acid change (Table 5).

Polymorphisms and allele frequencies found in the HESX1 and IGFBP-3 genes are shown in Tables 6 and 7, respectively. Only one SNP in HESX1 was a nonsynonymous substitution, whereas all the polymorphisms identified in IGFBP-3 were located in the noncoding regions, including a guanine deletion and a mutation (SNP3) located on the 3'-UTR region, with a frequency of 0.63 for the native allele and 0.36 for the new allele.

Genetics and Molecular Research 15 (3): gmr.15038762 
Table 5. SNPs located within the GHR gene in ROMO and BON cattle breeds.

\begin{tabular}{l|c|c|c|c|c|c}
\hline & SNP1 & SNP2 & SNP3 & SNP4 & SNP5 & SNP6 \\
\hline \multirow{2}{*}{ Genotype } & G $>$ A & C $>$ T & A $>$ G & A $>$ C & G $>$ A & A $>$ G \\
\hline \multirow{2}{*}{ Allele frequency } & Ser (AGC) & Pro (CCC) & Asn (AAC) & Asn (AAC) & Ala (GCC) & Ser (AGC) \\
\cline { 2 - 7 } & Asn (AAC) & Ser (TCC) & Asp (GAC) & Thr (ACC) & Thr (ACC) & Gly (GGC) \\
\cline { 2 - 7 } & $\mathrm{G}(97.4 \%)$ & $\mathrm{C}(97.4 \%)$ & $\mathrm{A}(92.3 \%)$ & $\mathrm{C}(52.6 \%)$ & $\mathrm{G}(98.7 \%)$ & $\mathrm{A}(56.4 \%)$ \\
\hline \multirow{2}{*}{ Genotype frequency } & $\mathrm{A}(2.6 \%)$ & $\mathrm{T}(2.6 \%)$ & $\mathrm{G}(7.7 \%)$ & $\mathrm{A}(47.4 \%)$ & $\mathrm{A}(1.3 \%)$ & $\mathrm{G}(43.6 \%)$ \\
\cline { 2 - 7 } & $07(94.9 \%)$ & $37(94.9 \%)$ & $33(84.6 \%)$ & $7(17.9 \%)$ & $38(97.4 \%)$ & $8(20.5 \%)$ \\
\cline { 2 - 7 } & $2(0.0 \%)$ & $0(0.0 \%)$ & $0(0.0 \%)$ & $5(12.8 \%)$ & $0(0.0 \%)$ & $3(7.7 \%)$ \\
\hline
\end{tabular}

Table 6. SNPs located within the HESX1 gene in ROMO and BON cattle breeds.

\begin{tabular}{l|c|c}
\hline & SNP1 & SNP2 \\
\hline Genotype & $\mathrm{C}>\mathrm{T}$ & $\mathrm{G}>\mathrm{A}$ \\
\hline \multirow{2}{*}{ AA change } & Pro (CCT) & No change \\
\cline { 2 - 3 } & $\mathrm{Leu}(\mathrm{CTT})$ & $\mathrm{G}(89.7 \%)$ \\
\cline { 2 - 3 } & $\mathrm{C}(89.7 \%)$ & $\mathrm{A}(10.3 \%)$ \\
\cline { 2 - 3 } & $\mathrm{T}(10.3 \%)$ & $31(79.5 \%)$ \\
\cline { 2 - 3 } & $31(79.5 \%)$ & $0(0.0 \%)$ \\
\cline { 2 - 3 } & $0(0.0 \%)$ & $8(20.5 \%)$ \\
\hline
\end{tabular}

Table 7. SNPs located within the IGFBP-3 gene in ROMO and BON cattle breeds.

\begin{tabular}{|c|c|c|c|c|c|}
\hline & SNP1 & SNP2 & SNP3 & SNP4 & SNP5 \\
\hline Genotype & $\mathrm{C}>\mathrm{G}$ & $\mathrm{C}>\mathrm{A}$ & $\mathrm{C}>\mathrm{T}$ & $\mathrm{T}>\mathrm{C}$ & Deletion G \\
\hline Position & Intron & Intron & UTR & Intron & Intron \\
\hline \multirow[t]{2}{*}{ Allele frequency } & $\mathrm{C}(89.2 \%)$ & $\mathrm{C}(64.9 \%)$ & C (63.9\%) & $\mathrm{T}(60.3 \%)$ & Normal $(89.7 \%)$ \\
\hline & $\mathrm{G}(10.8 \%)$ & $\mathrm{A}(35.1 \%)$ & $\mathrm{T}(36.1 \%)$ & $\mathrm{C}(39.7 \%)$ & Deletion $(10.3 \%)$ \\
\hline \multirow[t]{3}{*}{ Genotype frequency } & $29(78.4 \%)$ & $13(35.1 \%)$ & $12(33.3 \%)$ & $9(23.1 \%)$ & Normal $(79.5 \%)$ \\
\hline & $0(0.0 \%)$ & $2(5.4 \%)$ & $2(5.6 \%)$ & $1(2.6 \%)$ & Delhomo (0.0\%) \\
\hline & $8(21.6 \%)$ & $22(59.5 \%)$ & $22(61.1 \%)$ & $29(74.4 \%)$ & Delhet $(20.5 \%)$ \\
\hline
\end{tabular}

\section{Association analysis}

The association analysis was performed on the whole set of polymorphisms found in the six analyzed genes, which were compared to the deregressed breeding values for WW, DWG, and W16M. Figures 1, 2, and 3 show the $-\log _{10} \mathrm{P}$ values for each marker affecting WW, DWG, and $\mathrm{W} 16 \mathrm{M}$, respectively, assuming five different models of genetic control, namely codominant, dominant, recessive, overdominant, and log-additive. Two threshold lines are shown in the figures, representing the statistically significant associations at nominal level (pink line; $\mathrm{P}<$ 0.05 ) and at Bonferroni correction level (red line; $\mathrm{P}<0.001$ ). A value below this $\mathrm{P}$ value can be accepted as a significant association between the SNP marker and the trait under study.

The analysis of WW showed 13 variants having significant association $(\mathrm{P}>0.05)$ with this trait. The SNP GhRE06.2 showed a P value close to the Bonferroni threshold. Under a dominant model, the significance of the association increased $(P<0.001)$ and surpassed the Bonferroni threshold. Similar results were obtained when overdominant and additive models were used, indicating the important effect of this variation on WW. In the individual analysis for this variant and after correcting for the fixed effects of sex and breed, the highest significant association $(\mathrm{P}=0.0002)$ and the lowest AIC value were obtained under a dominant model. 
Novel SNPs linked to growth traits in creole cattle

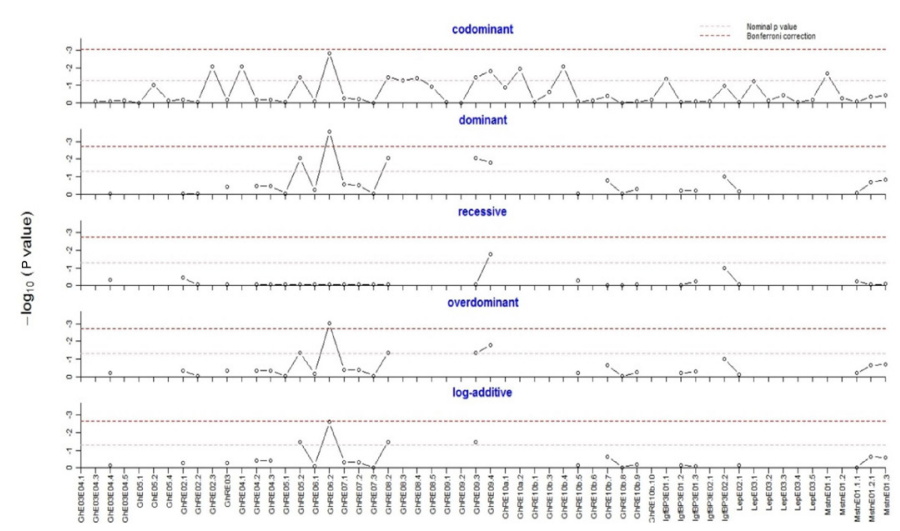

Figure 1. Effect of new variants on the genetic value of weaning weight in Colombian creole cattle breeds.

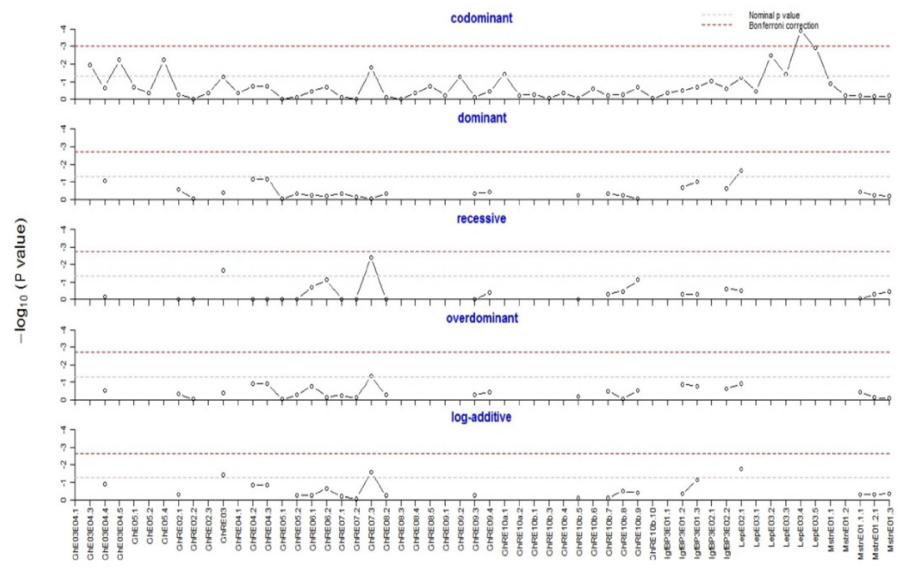

Figure 2. Effect of new variants on the genetic value of daily weight gain in Colombian creole cattle breeds.

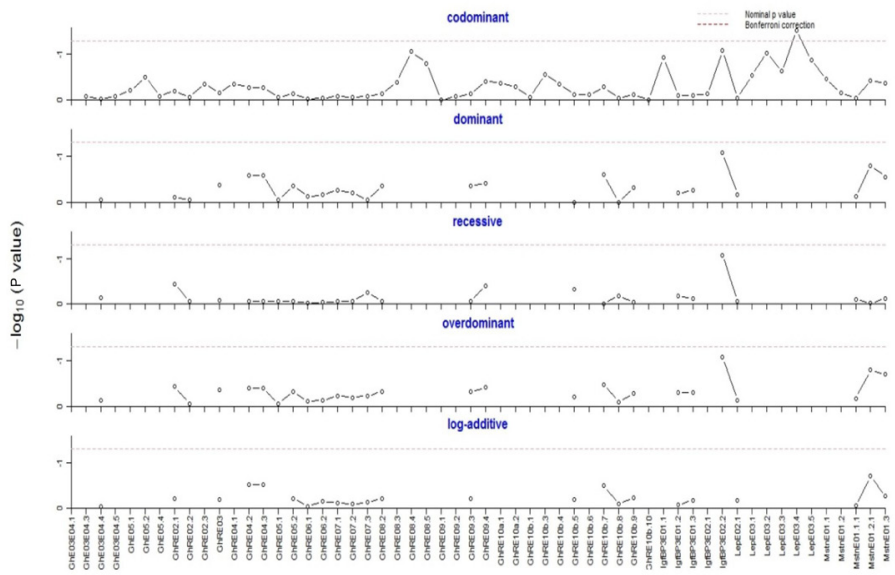

Figure 3. Effect of new variants on the genetic value of weight at 16 months in Colombian creole cattle breeds.

Genetics and Molecular Research 15 (3): gmr.15038762 
Animals with the homozygous TT or heterozygous CT genotypes demonstrated a lower mean value for WW than animals with the homozygous CC genotype, with a mean difference of $124.15 \mathrm{~kg}$ between the genotypes (Table 8). A similar situation was observed when an overdominant model was assumed, in which the animals with CC and TT genotypes had a higher value compared to the animals with the heterozygous genotype $(\mathrm{P}=0.0009)$. The effects of SNPs on DWG and W16M are shown in Figures 2 and 3, respectively.

Table 8. Effect of the SNP GhRE06.2 on WW variation in BON and ROMO cattle breeds.

\begin{tabular}{|c|c|c|c|c|c|c|}
\hline Model & $\mathrm{N}$ & Means \pm SE & Difference & Range & $\mathrm{P}$ value & AIC \\
\hline \multicolumn{7}{|c|}{ Codominant } \\
\hline $\mathrm{C} / \mathrm{C}$ & 51 & $-1.2 \pm 5.8$ & 0.0 & & 0.00140 & 1097 \\
\hline $\mathrm{C} / \mathrm{T}$ & 35 & $-40.4 \pm 30.6$ & -124.83 & -192.4 to -57.3 & & \\
\hline $\mathrm{T} / \mathrm{T}$ & 3 & $13.3 \pm 0.8$ & -103.63 & -247.4 to 40.2 & & \\
\hline \multicolumn{7}{|l|}{ Dominant } \\
\hline $\mathrm{C} / \mathrm{C}$ & 51 & $-1.2 \pm 5.8$ & 0 & & 0.00028 & 1095 \\
\hline $\mathrm{C} / \mathrm{T}-\mathrm{T} / \mathrm{T}$ & 38 & $-36.2 \pm 28.2$ & -124.15 & -191.2 to -57.1 & & \\
\hline \multicolumn{7}{|l|}{ Recessive } \\
\hline $\mathrm{C} / \mathrm{C}-\mathrm{C} / \mathrm{T}$ & 86 & $-17.1 \pm 12.9$ & 0 & & 0.93247 & 1108 \\
\hline $\mathrm{T} / \mathrm{T}$ & 3 & $13.3 \pm 0.8$ & 6.05 & -134.0 to 146.1 & & \\
\hline \multicolumn{7}{|c|}{ Overdominant } \\
\hline $\mathrm{C} / \mathrm{C}-\mathrm{T} / \mathrm{T}$ & 54 & $-0.4 \pm 5.5$ & 0 & & 0.00090 & 1097 \\
\hline $\mathrm{C} / \mathrm{T}$ & 35 & $-40.4 \pm 30.6$ & -104.74 & -166.6 to -42.9 & & \\
\hline \multicolumn{7}{|c|}{ log-Additive } \\
\hline $0,1,2$ & & & -92.21 & -151.5 to -32.9 & 0.00232 & 1098 \\
\hline
\end{tabular}

Several polymorphisms were associated with DWG. Among them, the SNPs GhR07.3, LepE03.1, LepE03.2, and Lep03.4 had the highest significant levels of association (Table 9). Animals with heterozygous genotypes for LepE03.1 showed better performance, with a mean difference of $53.02 \mathrm{~g}$ over the mean value in the homozygous animals. LepE03.2 also had a significant $\mathrm{P}$ value $(\mathrm{P}=0.003)$ but a lower difference between the genotypes $(35.06 \mathrm{~g})$. The marker with highest effect on DWG was LepE03.4 $(\mathrm{P}=0.0001)$, which was a synonymous substitution. The performance of animals with heterozygous genotypes was better (49.64 g) than that of individuals with homozygous genotype.

\begin{tabular}{|c|c|c|c|c|c|c|}
\hline Codominant & $\mathrm{N}$ & Mean \pm SE & Difference & Range & $P$ value & AIC \\
\hline \multicolumn{7}{|l|}{ LepE03.1 } \\
\hline $\mathrm{C} / \mathrm{C}$ & 57 & $-28.9 \pm 19.4$ & 0.0 & & 0.05 & 1104 \\
\hline $\mathrm{C} / \mathrm{T}$ & 32 & $6.7 \pm 1.3$ & 53.0 & -1.8 to 107.8 & & \\
\hline \multicolumn{7}{|l|}{ LepE03.2 } \\
\hline$\overline{\mathrm{C} / \mathrm{C}}$ & 24 & $-9.5 \pm 16.8$ & 0.0 & & 0.003435 & 952 \\
\hline $\mathrm{C} / \mathrm{T}$ & 65 & $23.2 \pm 3.7$ & 35.1 & 11.6 to 58.6 & & \\
\hline \multicolumn{7}{|l|}{ LepE03.3 } \\
\hline $\mathrm{T} / \mathrm{T}$ & 31 & $1.2 \pm 13.5$ & 0.0 & & 0.03686 & 956.1 \\
\hline $\mathrm{T} / \mathrm{C}$ & 58 & $21.4 \pm 4.1$ & 24.5 & 1.5 to 47.5 & & \\
\hline \multicolumn{7}{|l|}{ LepE03.4 } \\
\hline $\bar{T} / \mathrm{T}$ & 17 & $-25.5 \pm 22.7$ & 0.0 & & 0.000124 & 946.4 \\
\hline $\mathrm{T} / \mathrm{C}$ & 72 & $23.8 \pm 3.4$ & 49.6 & 24.3 to 74.9 & & \\
\hline \multicolumn{7}{|l|}{$\begin{array}{l}\text { LepE03.5 } \\
\end{array}$} \\
\hline $\mathrm{C} / \mathrm{C}$ & 23 & $-12.9 \pm 17.3$ & 0.0 & & 0.00117 & 950.2 \\
\hline $\mathrm{C} / \mathrm{T}$ & 66 & $23.9 \pm 3.7$ & 38.9 & 15.4 to 62.4 & & \\
\hline
\end{tabular}


For W16M, the variants GhRE08.4, IgBP3E02.2, and LepE03.2 were significantly associated with this trait $(\mathrm{P}<0.005)$, without exceeding the threshold imposed by the Bonferroni threshold. Only the SNP LepE03.4 was found to be highly associated with this trait and surpassed the threshold imposed by the Bonferroni test (Table 10). In the association analysis for the breeding values of W16M, deregressed by breed and sex effects, the SNPs GhRE08.4 and IgBP3E02.2 had significant effects $(\mathrm{P}<0.005)$, but could not surpass the Bonferroni threshold. Only the former was observed to be significant under a codominant model whereas the latter was significantly associated with all the tested models except for the additive model. Likewise, two variants in LEPT (LepE03.2 and LepE03.4) demonstrated a significant effect $(\mathrm{P}<0.005)$ on this trait, but only LepE03.4 surpassed the threshold of the Bonferroni threshold, indicating its high association with W16M. Under the codominant model $(\mathrm{P}=0.029)$, individuals with a heterozygous genotype showed the highest performance with a difference of $5273 \mathrm{~kg}$ compared to the mean value obtained for the homozygous genotypes.

Table 10. Effect of the SNP LepE03.4 on W16M variation in BON and ROMO cattle breeds.

\begin{tabular}{l|c|c|c|c|c|c}
\hline Model & $\mathrm{N}$ & Mean $\pm \mathrm{SE}$ & Difference & Range & P value & AIC \\
\hline Codominant & & & & & & \\
\hline $\mathrm{T} / \mathrm{T}$ & 17 & $-46.6 \pm 50.2$ & 0.0 & & 0.02985 & 1059 \\
\hline $\mathrm{T} / \mathrm{C}$ & 72 & $8.3 \pm 1.1$ & 52.7 & 5.1 to 100.3 & & \\
\hline $\log$-Additive & & & & & & \\
\hline $0,1,2$ & & & 52.7 & 5.1 to 100.3 & & 1059 \\
\hline
\end{tabular}

\section{DISCUSSION}

New SNPs were identified in Colombian BON and ROMO cattle breeds. Several polymorphisms were located within the coding regions of genes involved in the physiological pathways. Molecular mechanisms regulating the expression of phenotypes of the growth traits were analyzed. Some of these new genomic variations influenced the amino acid composition of proteins, such as growth hormone, growth hormone receptor, leptin, myostatin, and the homeobox protein ANF. However, all the SNPs identified in the gene that codes for the IGFBP-3 were located in the non-coding regions of DNA.

Several studies have reported genomic mutations within genes involved in the expression of proteins of the GH-IGF axis. Lagziel and Soller (1999) identified a transversion on the exon $\mathrm{V}$ of $\mathrm{GH}$. The mutation $\mathrm{C}>\mathrm{G}$ causes an amino acid substitution (Leu $>\mathrm{Val}$ ) at position 127 of the polypeptide and the association study revealed that animals with the VV genotype displayed a lower growth rate than the individuals with LL or LV genotypes. The VV individuals showed a lower DWG, BW, and carcass yield (Grochowska et al., 2001b). In the present study, three of the 10 SNPs found in GH changed the amino acid composition of the growth hormone, although none of them was associated with growth traits at the significance level set by the Bonferroni test. Similarly, Di Stasio et al. (2002) did not find any significant association between polymorphisms on GH with meat production traits in Piedmontese cattle. Likewise, other mutations located in genes of the somatotropic axis like IGFBP-3, were not associated with growth in BON and ROMO, which contrasts with other reports. Choudhary et al. (2007) observed a significant effect of an IGFBP-3 polymorphism on birth weight and BW at 12,18 , and 24 months of age in crossbred calves, with an improved growth performance observed in heterozygous individuals. The lack of association between SNPs producing amino acid substitutions and growth traits in BON and ROMO might be due to breed-specific

Genetics and Molecular Research 15 (3): gmr.15038762 
epistatic interactions in which the expression of proteins with new coded sequences depends on the expression of other proteins to reach threshold levels of these molecules, limiting the effective variation in the phenotype of the analyzed growth traits.

In contrast, some polymorphisms located in other genes involved in the GH-IGF axis were associated with growth traits in BON and ROMO. From the high number of SNPs identified on GHR, the mutation GhRE06.2 was significantly associated with WW, being the only trait, statistically significant as determined by the Bonferroni test, under at least two different genetic models. Furthermore, the SNPs GhRE05.2 and GhRE07.3 were significantly associated with WW and DWG, respectively, and despite not surpassing the Bonferroni correction threshold, they were significant under multiple genetic models tested. It might be possible that genomic variations in the genes coding for this receptor played a more important role in the expression of growth traits in $\mathrm{BON}$ and $\mathrm{ROMO}$, rather than the genomic variations in genes coding for carrier proteins and molecules like the growth hormone or the insulinlike growth factors of the somatotropic axis. Other studies have found associations between some substitutions in the amino acid sequence of this receptor and major effects on milk yield and composition (Blott et al., 2003; Viitala et al., 2006). Moreover, several other bovine GHR sequence polymorphisms (Falaki et al., 1996; Ge et al., 2000; Ge et al., 2003; Sherman et al., 2008) and a microsatellite marker (GT repetition) in a promoter region of this gene (Hale et al., 2000) have been identified, with the larger allele (16 to 20 GT repetitions) of this last polymorphism having a significant association with the WW and carcass weight. In the present study, the SNPs GhR4 and GhR6 in the exons IV and VI, respectively, showed similar allelic frequencies that were near to the equilibrium, indicating their potential importance for association analysis. Other variations (SNP rGH1, SNP rGH2, SNP rGH3, and SNP rGH5) showed a high disequilibrium between the frequencies of their alleles.

Some mutations identified in genes not directly involved in the GH-IGF axis were also associated with growth traits. The eight new variants identified in LEPT were located at positions different from those reported by Buchanan et al. (2002). Lagonigro et al. (2003) and Nkrumah et al. (2005) have also reported mutations in other regions of this gene. In some cases (Nkrumah et al., 2004), the variants have been found within the exon II, as was found in our study, and sometimes in the promoter region (Nkrumah et al., 2005). Several of these polymorphisms have been associated with feed intake, milk yield, carcass weight, and reproduction-related traits (van der Lende et al., 2005). In the present study, the SNP Lep03.4 showed a significant effect on DWG, surpassing the significance level set by the Bonferroni test $(\mathrm{P}=0.0002)$, under a codominant model. Similarly, three SNPs located near this variation showed a significant effect on DWG but the significance was below the Bonferroni threshold. These markers might be in LD with the SNP LepE03.4. Furthermore, there was a significant association between the SNP LepE03.4 and W16M, although the significance did not surpass the Bonferroni threshold. The significant association of this SNP with both DWG and W16M suggests that it might be located close to a DNA region with a key role in the genetic control of growth traits.

Significant associations between growth traits and polymorphisms in LEPT have also been reported in goats (Wang et al., 2015), whereas other studies have demonstrated the associations of LEPT mutations with the carcass and meat quality traits in cattle (Tian et al., 2013). These associations are possibly explained by the role that leptin plays in the energy metabolic regulation through its action on the hypothalamic-pituitary-adrenal axis, with subsequent effects on the growth process of different species (Delavaud et al., 2002). Several polymorphisms in LEPT and GHR that have been associated with growth traits in cattle are shown in Table 11.

Genetics and Molecular Research 15 (3): gmr.15038762 
Most of the mutations in both GHR and LEPT have been reported within the same chromosome and genomic regions where the SNPs in these genes were identified in the present study.

Table 11. Polymorphisms on the GHR and LEPT genes associated with production traits in beef and dairy cattle.

\begin{tabular}{|c|c|c|c|c|c|}
\hline Gene & SNP & DNA Position & Traits/Comments & P value & References \\
\hline \multirow[t]{6}{*}{ GHR 20: $31,890,736-32,064,200$} & GhRE06.2 & 20:31916336 & WW & 0.0003 & Present study \\
\hline & GhRE08.4 & 20:31909580 & W16M & 0.005 & Present study \\
\hline & rs 109203152 & 20:32079536 & $\begin{array}{l}\text { Fat thickness at the 12th rib, } \\
\text { intramuscular fat, longissimus muscle } \\
\text { area in Brangus }\end{array}$ & 0.0618 & (Baeza et al., 2011) \\
\hline & rs 41638175 & 20:9732487 & $\begin{array}{l}\text { Carcass weight, lean meat yield in } \\
\text { Holstein }\end{array}$ & 0.001 & (Doran et al., 2014) \\
\hline & rs 109203152 & 20:32079536 & Fat thickness at the 12th rib & 0.0204 & (Garrett et al., 2008) \\
\hline & rs 109563545 & 20: 15870897 & $\begin{array}{l}\text { Shear force in Charolaise, Hereford, } \\
\text { Limousine }\end{array}$ & $<0.05$ & (McClure et al., 2012) \\
\hline \multirow{13}{*}{ Leptin 4: 93,249,874-93,266,624 } & LepE03.1 & 4: 93263980 & DWG & 0.05 & Present study \\
\hline & LepE03.2 & 4: 93264136 & DWG & 0.003 & Present study \\
\hline & LepE03.3 & 4: 93264139 & DWG & 0.04 & Present study \\
\hline & LepE03.4 & 4: 93264151 & $\begin{array}{l}\text { DWG } \\
\text { W16M }\end{array}$ & $\begin{array}{l}0.0001 \\
0.0299\end{array}$ & Present study \\
\hline & LepE03.5 & 4: 93264235 & DWG & 0.00117 & Present study \\
\hline & $\begin{array}{l}\text { UASMS2 } \\
\text { rs } 29004488\end{array}$ & $\begin{array}{c}528 \text { bp in the bovine leptin } \\
\text { promoter (Accession No. } \\
\text { AB070368) } \\
4: 93262056\end{array}$ & $\begin{array}{l}\text { Serum leptin }(\mathrm{ng} / \mathrm{ml}) \\
\text { Marbling score } \\
\text { Feed intake } \\
\text { Growth rate } \\
\text { Metabolic BW } \\
\text { Backfat thickness (mm) }\end{array}$ & $\begin{array}{c}0.001 \\
0.01 \\
<0.001 \\
<0.05 \\
<0.05 \\
0.001\end{array}$ & (Nkrumah et al., 2005) \\
\hline & & & Carcass yield and backfat thickness & $<0.05$ & (Corva et al., 2009) \\
\hline & UASMS3 & $\begin{array}{c}1759 \text { bp in the bovine leptin } \\
\text { promoter (Accession No. } \\
\text { AB070368) }\end{array}$ & $\begin{array}{l}\text { Feed intake } \\
\text { Growth rate } \\
\text { BW }\end{array}$ & $\begin{array}{l}0.001 \\
<0.10 \\
<0.01\end{array}$ & (Nkrumah et al., 2005) \\
\hline & LEP-2470 & 4: 95675400 & $\begin{array}{l}\text { Milk protein concentration (Holstein) } \\
\text { Milk yield (Holstein) }\end{array}$ & $\begin{array}{l}<0.05 \\
<0.1\end{array}$ & \multirow[t]{5}{*}{ (Giblin et al., 2010) } \\
\hline & LEP-1238 & 4: 95676628 & $\begin{array}{l}\text { Milk fat and protein concentration } \\
\text { (Holstein) }\end{array}$ & $<0.05$ & \\
\hline & LEP-963 & 4: 95676903 & $\begin{array}{l}\text { Milk fat and protein concentration } \\
\text { (Holstein) }\end{array}$ & $<0.05$ & \\
\hline & $\mathrm{R} 25 \mathrm{C}$ & 4: 95690050 & $\begin{array}{l}\text { Milk fat and protein concentration } \\
\text { (Holstein) }\end{array}$ & $<0.05$ & \\
\hline & Y7F & 4: 95689996 & $\begin{array}{l}\text { Angularity (Holstein) } \\
\text { Milk protein yield (Holstein) } \\
\text { Body condition score, milk yield } \\
\text { (Holstein) }\end{array}$ & $\begin{array}{l}<0.01 \\
<0.05 \\
<0.1\end{array}$ & \\
\hline
\end{tabular}

Mutations located in genes like HESX1 and MSTN were not associated with growth traits in BON and ROMO, with the exception of the SNP MstnE01.1 that was found to be significantly associated with WW, but without surpassing the significance threshold in the Bonferroni test. Moreover, as with other SNPs located in GHR, these mutations were significant only under a codominant model. In contrast, a gradual decrease in the significance levels was observed, with a higher number of variants showing association with WW compared to DWG and W16M. This might suggest that the growth traits expressed later (like W16M) are characteristics whose phenotypic expression cannot be easily predicted from the genetic profile of the individual, because they depend on the permanent and temporary environmental effects to a greater extent than the traits expressed earlier in life (like WW).

The SNPs significantly associated with growth traits in the present study could represent a pool of molecular candidates with high potential to improve the productivity in beef farms, through the implementation of breeding programs and the use of Colombian creole breeds. Moreover, all the SNPs identified, including those that were not significantly associated with the analyzed traits, might be considered in future studies to analyze different productive characteristics with other growth-related genes in livestock. 


\title{
Conflicts of interest
}

The authors declare no conflicts of interest.

\section{ACKNOWLEDGMENTS}

\author{
Research supported by the Ministry of Agriculture and Rural Development of
} Colombia.

\section{REFERENCES}

Arango J, Echeverri JJ and López A (2014). Association between a polymorphism in intron 3 of the bovine growth hormone gene and growth traits in Holstein heifers in Antioquia. Genet. Mol. Res. 13: 6191-6199. http://dx.doi. org/10.4238/2014.August.15.1

Baeza MC, Corva PM, Soria LA, Rincon G, et al. (2011). Genetic markers of body composition and carcass quality in grazing Brangus steers. Genet. Mol. Res. 10: 3146-3156.http://dx.doi.org/10.4238/2011.December.19.3

Bejarano D, Pedraza A, Rocha JF and Martínez R (2012). Genetic variability in commercial subpopulations of creole columbian breed Romosinuano. Revista CORPOICA, Vol 13 - No. 1, Enero - Junio, 97-107.

Biswas TK, Bhattacharya TK, Narayan AD, Badola S, et al. (2003). Growth hormone gene polymorphism and its effect on birth weight in cattle and buffalo. Asian-australas. J. Anim. Sci. 16: 494-497. http://dx.doi.org/10.5713/ajas.2003.494

Blott S, Kim J-J, Moisio S, Schmidt-Küntzel A, et al. (2003). Molecular dissection of a quantitative trait locus: a phenylalanine-to-tyrosine substitution in the transmembrane domain of the bovine growth hormone receptor is associated with a major effect on milk yield and composition. Genetics 163: 253-266.

Breier BH (1999). Regulation of protein and energy metabolism by the somatotropic axis. Domest. Anim. Endocrinol. 17: 209-218. http://dx.doi.org/10.1016/S0739-7240(99)00038-7

Buchanan FC, Fitzsimmons CJ, Van Kessel AG, Thue TD, et al. (2002). Association of a missense mutation in the bovine leptin gene with carcass fat content and leptin mRNA levels. Genet. Sel. Evol. 34: 105-116. http://dx.doi. org/10.1186/1297-9686-34-1-105

Corva PM, Fernández Macedo GV, Soria LA, Papaleo Mazzucco J, et al. (2009). Effect of leptin gene polymorphisms on growth, slaughter and meat quality traits of grazing Brangus steers. Genet. Mol. Res. 8: 105-116. http://dx.doi. org/10.4238/vol8-1gmr556

Chagas LM, Bass JJ, Blache D, Burke CR, et al. (2007). Invited review: New perspectives on the roles of nutrition and metabolic priorities in the subfertility of high-producing dairy cows. J. Dairy Sci. 90: 4022-4032. http://dx.doi. org/10.3168/jds.2006-852

Choudhary V, Kumar P, Bhattacharya TK, Bhushan B, et al. (2007). DNA polymorphism of insulin-like growth factorbinding protein-3 gene and its association with birth weight and body weight in cattle. J. Anim. Breed. Genet. 124: 29-34. http://dx.doi.org/10.1111/j.1439-0388.2007.00626.x

Cunningham MJ, Clifton DK and Steiner RA (1999). Leptin's actions on the reproductive axis: perspectives and mechanisms. Biol. Reprod. 60: 216-222. http://dx.doi.org/10.1095/biolreprod60.2.216

Delavaud C, Ferlay A, Faulconnier Y, Bocquier F, et al. (2002). Plasma leptin concentration in adult cattle: effects of breed, adiposity, feeding level, and meal intake. J. Anim. Sci. 80: 1317-1328.

Di Stasio L, Sartore S and Albera A (2002). Lack of association of GH1 and POU1F1 gene variants with meat production traits in Piemontese cattle. Anim. Genet. 33: 61-64. http://dx.doi.org/10.1046/j.1365-2052.2002.00811.x

Doran AG, Berry DP and Creevey CJ (2014). Whole genome association study identifies regions of the bovine genome and biological pathways involved in carcass trait performance in Holstein-Friesian cattle. BMC Genomics 15: 837. http://dx.doi.org/10.1186/1471-2164-15-837

Ehrich M, Böcker S and van den Boom D (2005). Multiplexed discovery of sequence polymorphisms using base-specific cleavage and MALDI-TOF MS. Nucleic Acids Res. 33: e38. http://dx.doi.org/10.1093/nar/gni038

Ewing B and Green P (1998). Base-calling of automated sequencer traces using phred. II. Error probabilities. Genome Res. 8: 186-194. http://dx.doi.org/10.1101/gr.8.3.186

Ewing B, Hillier L, Wendl MC and Green P (1998). Base-calling of automated sequencer traces using phred. I. Accuracy assessment. Genome Res. 8: 175-185.http://dx.doi.org/10.1101/gr.8.3.175

Genetics and Molecular Research 15 (3): gmr.15038762 
Falaki M, Gengler N, Sneyers M, Prandi A, et al. (1996). Relationships of polymorphisms for growth hormone and growth hormone receptor genes with milk production traits for Italian Holstein-Friesian bulls. J. Dairy Sci. 79: 1446-1453. http://dx.doi.org/10.3168/jds.S0022-0302(96)76503-7

Garcia MR, Amstalden M, Williams SW, Stanko RL, et al. (2002). Serum leptin and its adipose gene expression during pubertal development, the estrous cycle, and different seasons in cattle. J. Anim. Sci. 80: 2158-2167.

Garrett AJ, Rincon G, Medrano JF, Elzo MA, et al. (2008). Promoter region of the bovine growth hormone receptor gene: single nucleotide polymorphism discovery in cattle and association with performance in Brangus bulls. J. Anim. Sci. 86: 3315-3323.http://dx.doi.org/10.2527/jas.2008-0990

Ge W, Davis ME, Hines HC and Irvin KM (2000). Rapid communication: Single nucleotide polymorphisms detected in exon 10 of the bovine growth hormone receptor gene. J. Anim. Sci. 78: 2229-2230.

Ge W, Davis ME, Hines HC, Irvin KM, et al. (2003). Association of single nucleotide polymorphisms in the growth hormone and growth hormone receptor genes with blood serum insulin-like growth factor I concentration and growth traits in Angus cattle. J. Anim. Sci. 81: 641-648.

Giblin L, Butler ST, Kearney BM, Waters SM, et al. (2010). Association of bovine leptin polymorphisms with energy output and energy storage traits in progeny tested Holstein-Friesian dairy cattle sires. BMC Genet. 11: 73. http:// dx.doi.org/10.1186/1471-2156-11-73

González JR, Armengol L, Solé X, Guinó E, et al. (2007). SNPassoc: an R package to perform whole genome association studies. Bioinformatics 23: 644-645. http://dx.doi.org/10.1093/bioinformatics/btm025

Gordon D, Abajian C and Green P (1998). Consed: a graphical tool for sequence finishing. Genome Res. 8: 195-202. http:// dx.doi.org/10.1101/gr.8.3.195

Grisolia AB, D'Angelo GT, Porto Neto LR, Siqueira F, et al. (2009). Myostatin (GDF8) single nucleotide polymorphisms in Nellore cattle. Genet. Mol. Res. 8: 822-830. http://dx.doi.org/10.4238/vol8-3gmr548

Grochowska R, Sørensen P, Zwierzchowski L, Snochowski M, et al. (2001a). Genetic variation in stimulated GH release and in IGF-I of young dairy cattle and their associations with the leucine/valine polymorphism in the GH gene. $J$. Anim. Sci. 79: 470-476.

Grochowska L, Zwierzchowski S, et al. (2001b). Association between gene polymorphism of growth hormone and carcass traits in dairy bulls. Anim. Sci. 72: 441-447.

Hale CS, Herring WO, Shibuya H, Lucy MC, et al. (2000). Decreased growth in angus steers with a short TG-microsatellite allele in the P1 promoter of the growth hormone receptor gene. J. Anim. Sci. 78: 2099-2104.

Houba PHJ and te Pas MFW (2004). The muscle regulatory factors gene family in relation to meat production. In: Muscle development of livestock animals: physiology, genetics and meat quality (te Pas MWF, Everts ME and Haagsman HP, eds.) Cromwell Press, Trowbridge, UK, 201-224.

Houseknecht KL, Baile CA, Matteri RL and Spurlock ME (1998). The biology of leptin: a review. J. Anim. Sci. 76: 1405-1420.

Houseknecht KL, Portocarrero CP, Ji S, Lemenager R, et al. (2000). Growth hormone regulates leptin gene expression in bovine adipose tissue: correlation with adipose IGF-1 expression. J. Endocrinol. 164: 51-57. http://dx.doi. org/10.1677/joe. 0.1640051

Lagonigro R, Wiener P, Pilla F, Woolliams JA, et al. (2003). A new mutation in the coding region of the bovine leptin gene associated with feed intake. Anim. Genet. 34: 371-374.http://dx.doi.org/10.1046/j.1365-2052.2003.01028.x

Lagziel A and Soller M (1999). DNA sequence of SSCP haplotypes at the bovine growth hormone (bGH) gene. Anim. Genet. 30: 362-365.http://dx.doi.org/10.1046/j.1365-2052.1999.00499.x

Lai X, Lan X, Chen H, Wang X, et al. (2009). A novel SNP of the Hesx1 gene in bovine and its associations with average daily gain. Mol. Biol. Rep. 36: 1677-1681.http://dx.doi.org/10.1007/s11033-008-9368-3

Larsson H, Elmståhl S, Berglund G and Ahrén B (1998). Evidence for leptin regulation of food intake in humans. J. Clin. Endocrinol. Metab. 83: 4382-4385.

Lord GM, Matarese G, Howard JK, Baker RJ, et al. (1998). Leptin modulates the T-cell immune response and reverses starvation-induced immunosuppression. Nature 394: 897-901.http://dx.doi.org/10.1038/29795

Lucy MC (2008). Functional differences in the growth hormone and insulin-like growth factor axis in cattle and pigs: implications for post-partum nutrition and reproduction. Reprod. Domest. Anim. 43 (Suppl 2): 31-39. http://dx.doi. org/10.1111/j.1439-0531.2008.01140.x

Martínez CG (1992). El ganado criollo colombiano Blanco Orejinegro (BON). Anim. Genet. Resour. Inf. 9: 27-35. http:// dx.doi.org/10.1017/S1014233900003175

Martínez CG (1998). El ganado criollo Romosinuano (Romo). Anim. Genet. Resour. Inf. 24: 1-11. http://dx.doi.org/10.1017/ $\underline{\mathrm{S} 1014233900001097}$

Martínez R, Gallego J, Onofre G, Pérez J, et al. (2009). Evaluación de la variabilidad y potencial genético de poblaciones de bovinos criollos colombianos. Anim. Genet. Resour. Inf. 44: 57-66. http://dx.doi.org/10.1017/S1014233900002868

Genetics and Molecular Research 15 (3): gmr.15038762 
Martínez R, Llina's AP and Rocha JF (2013). Genetic variability in Blanco Orejinegro breed cattle population in Colombia. Genet. Mol. Res. 12: 1083-1094.

Marínez R, gómez Y and Rocha JF (2014). Genome-wide association study on growth traits in Colombian creole breeds and crossbreeds with Zebu cattle. Genet. Mol. Res. 13: 6420-6432.

McClure Mc, Ramey HR, Rolf MM, McKay SD, et al. (2012). Genome-wide association analysis for quantitative trait loci influencing Warner-Bratzler shear force in five taurine cattle breeds. Anim. Genet. 43: 662-673.

Nickerson DA, Tobe VO and Taylor SL (1997). PolyPhred: automating the detection and genotyping of single nucleotide substitutions using fluorescence-based resequencing. Nucleic Acids Res. 25: 2745-2751. http://dx.doi.org/10.1093/ $\underline{\operatorname{nar} / 25.14 .2745}$

Nkrumah JD, Li C, Basarab JB, Guercio S, et al. (2004). Association of a single nucleotide polymorphism in the bovine leptin gene with feed intake, feed efficiency, growth, feed behaviour, carcass quality and body composition. Can. J. Anim. Sci. 84: 211-219. http://dx.doi.org/10.4141/A03-033

Nkrumah JD, Li C, Yu J, Hansen C, et al. (2005). Polymorphisms in the bovine leptin promoter associated with serum leptin concentration, growth, feed intake, feeding behavior, and measures of carcass merit. J. Anim. Sci. 83: 20-28.

Pereira AP, Alencar MM de, Oliveira HN de and Regitano LC de A (2005). Association of GH and IGF-1 polymorphisms with growth traits in a synthetic beef cattle breed. Genet. Mol. Biol. 28: 230-236. http://dx.doi.org/10.1590/S1415$\underline{47572005000200009}$

Rehfeldt C, Fiedler I and Stickland NC (2004). In: Number and size of muscle fibres in relation to meat production. Muscle development of livestock animals: physiology, genetics and meat quality (Pas MWF te, Everts ME and Haagsman HP, eds.) Cromwell Press, Trowbridge, UK, 1-38.

Rocha JF, Gallego JL, Vásquez RF, Pedraza JA, et al. (2012). Estimation of genetic parameters for age at first calving and calving interval in Blanco Orejinegro (BON) breed cattle populations in Colombia. Rev. Colomb. Cienc. Pecu. 25: $220-228$.

Rozen S and Skaletsky H (2000). Primer3 on the WWW for general users and for biologist programmers. Methods Mol. Biol. 132: 365-386.

Sambrook J and Russell D (2001). Molecular Cloning: A Laboratory Manual, 3rd eds. Cold Spring Harbor Laboratory Press, Cold Spring Harbor, NY.

Sarti FM, Lasagna E, Ceccobelli S, Di Lorenzo P, et al. (2014). Influence of single nucleotide polymorphisms in the myostatin and myogenic factor 5 muscle growth-related genes on the performance traits of Marchigiana beef cattle. J. Anim. Sci. 92: 3804-3810.http://dx.doi.org/10.2527/jas.2014-7669

Sherman EL, Nkrumah JD, Murdoch BM, Li C, et al. (2008). Polymorphisms and haplotypes in the bovine neuropeptide $\mathrm{Y}$, growth hormone receptor, ghrelin, insulin-like growth factor 2, and uncoupling proteins 2 and 3 genes and their associations with measures of growth, performance, feed efficiency, and carcass merit in beef cattle. J. Anim. Sci. 86: 1-16.http://dx.doi.org/10.2527/jas.2006-799

Takagi M, Takahashi M, Ohtsu Y, Sato T, et al. (2016). A novel mutation in HESX1 causes combined pituitary hormone deficiency without septo optic dysplasia phenotypes. Endocr. J. 63: 405-410.http://dx.doi.org/10.1507/endocrj.EJ15-0409

Tian J, Zhao Z, Zhang L, Zhang Q, et al. (2013). Association of the leptin gene E2-169T $>$ C and E3-299T $>$ A mutations with carcass and meat quality traits of the Chinese Simmental-cross steers. Gene 518: 443-448. http://dx.doi. org/10.1016/j.gene.2012.11.071

Tuggle CK and Trenkle A (1996). Control of growth hormone synthesis. Domest. Anim. Endocrinol. 13: 1-33. http:// dx.doi.org/10.1016/0739-7240(95)00059-3

van der Lende T, Te Pas MF, Veerkamp RF and Liefers SC (2005). Leptin gene polymorphisms and their phenotypic associations. Vitam. Horm. 71: 373-404. http://dx.doi.org/10.1016/S0083-6729(05)71013-X

Vásquez R, Martínez R, Rodríguez O, Ballesteros H, et al. (2007). Manual de conservacion, multiplicacion y mejoramiento de las razas bovinas criollas colombianas. 1st edn. Produmedios, Mosquera (Cundinamarca).

Velazquez MA, Spicer LJ and Wathes DC (2008). The role of endocrine insulin-like growth factor-I (IGF-I) in female bovine reproduction. Domest. Anim. Endocrinol. 35: 325-342.http://dx.doi.org/10.1016/j.domaniend.2008.07.002

Viitala S, Szyda J, Blott S, Schulman N, et al. (2006). The role of the bovine growth hormone receptor and prolactin receptor genes in milk, fat and protein production in Finnish Ayrshire dairy cattle. Genetics 173: 2151-2164. http:// dx.doi.org/10.1534/genetics.105.046730

Wang C, Zhang H, Niu L, Guo J, et al. (2015). The novel SNPs of leptin gene and their associations with growth traits in Chinese Nanjiang Yellow goat. Gene 572: 35-41.http://dx.doi.org/10.1016/j.gene.2015.06.073

Woods SC, Seeley RJ, Porte D, Jr. and Schwartz MW (1998). Signals that regulate food intake and energy homeostasis. Science 280: 1378-1383. http://dx.doi.org/10.1126/science.280.5368.1378

Genetics and Molecular Research 15 (3): gmr.15038762 